\title{
Electrohydrodynamic (EHD) drying: fundamentals and applications
}

\section{Martynenko, A. ; Kudra, T.}

Department of Engineering, Faculty of Agriculture, Dalhousie University, Truro, NS, Canada

*E-mail of the corresponding author: alex.martynenko@dal.ca

\begin{abstract}
Following background to the phenomenon of electrohydrodynamics with concise review of basic features like shorter drying time, lower energy consumption and better product quality, the selected key factors affecting EHD drying are examined. These include the geometry of discharge electrodes, effects of air humidity on drying rate, depression of material temperature, and cooling effect of ionic wind.

Examples are given for: (i) prototype EHD dryers of multi-belt types, and (ii) pilot-scale multi-belt EHD dryer in vertical arrangement that can be aggregated into one unit of higher capacity, and vertical cylindrical EHD dryer with vibrated shelves.
\end{abstract}

Keywords: ionic wind; corona discharge; drying; energy; quality. 


\section{Introduction}

Electrohydrodynamic (EHD) drying appears to be a viable technology alternative to conventional thermal drying for certain thermally-labile materials, such as high-value bioactive components of fruits and medicinal plants (polyphenols, flavonoids, dietary fiber, etc.), living cells (bacteria, yeasts and viruses), and non-living substances of biological origin (blood plasma, serum, hormones, antibiotics, probiotics, nutraceuticals, etc.). ${ }^{[1-4]}$

The benefits of EHD compared to hot air drying on food quality include lesser shrinkage ${ }^{[15}$, ${ }^{16]}$, higher rehydration ratio ${ }^{[15]}$, preserved content of ascorbic acid (vitamin C) ${ }^{[17]}$ and no discernible color degradation ${ }^{[16-20]}$, though $\mathrm{Li}$ et al ${ }^{[21]}$ reported distinctive browning of okara cake just under the needle electrode. The quality-related benefits can be attributed to increased drying rate respectively by 1.5 to 4 times at high $\left(5 \mathrm{~ms}^{-1}\right)$ and low $\left(1 \mathrm{~ms}^{-1}\right)$ cross-

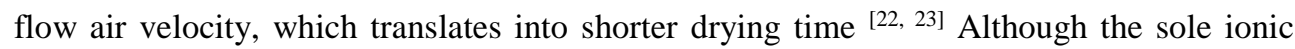
wind can favorably affect mass transfer, the combinations of EHD with low-temperature air drying ${ }^{[4-6]}$, vacuum freeze drying ${ }^{[7]}$ and auxiliary contact heating ${ }^{[8]}$ have also been reported.

Energy consumption in EHD drying is much lower than that in hot air drying, likely because of targeted supply of energy for moisture evaporation and practically no heat lost with exhaust air. However, the favorable low energy consumption given in published papers is based on the "net" energy calculated from the applied voltage and current. Even though the real energy consumption by EHD and peripheral equipment ranges from 90 to $5000 \mathrm{kJkg}^{-1}[2]$ it is still attractive for end used of EHD dryers. The energy-related issues in EHD drying have been reviewed by Kudra and Martynenko. ${ }^{[23]}$

Aside from purely experimental research on EHD drying of apples, carrot, potato, tomato, mushrooms, spinach, rapeseed, grapes blueberry, cranberry, etc., as well as model materials such as water, paper tissue, agar gel, wet sand and glass, theoretical studies on EHD drying are focused on determination of the ionic wind characteristics, such as space charge and corona current distributions ${ }^{[9,10]}$ or numerical solution of the mathematical model with experimental validation through drying experiments. ${ }^{[11-14]}$

Electrohydrodynamic (EHD) drying relies on the so-called corona (electric or ionic wind), originating from a sharp electroconductive needle or horizontal fine wire under high AC or DC voltage. ${ }^{[24]}$ As a result, ions leaving discharge electrode impinge the surface of the drying material located on the metallic and electrically grounded plate-type electrode. The partially ionized gas molecules along with residual non-charged molecules create a jet-type gas flow between the discharge (needle or wire) electrode and the collecting (solid or perforated plate) electrode. Since some factors affecting EHD drying (e.g., voltage, current, temperature) are well presented in topical literature ${ }^{[25]}$, this paper is focused on less elaborated factors, such as desirable geometry of electrodes and air humidity on EHD drying. Examples of large-scale dryers are also given. 


\section{Key factors in EHD drying}

\subsection{Geometry of discharge electrode}

The fundamental studies on EHD drying were performed mostly with a single pin or wire, and only few of them used multi-pin electrodes, yet placed arbitrarily regarding geometrical arrangement (e.g., rectangular or triangular) and spacing between pins. However, because of conical form of the ionic wind ${ }^{[26]}$, the impact surface of the wind from a single pin electrode on the plate electrode is circular unless disturbed by the air cross-flow, for example. Referring to multi-pin electrode it is intuitive to expect that the minimum distance between pins at a definite pin-to-material gap should result in a series of circular areas on the material surface which almost touch each other. ${ }^{[22]}$

It should be noted that the gaseous jet of ionic wind impinging the material under drying rebounds from the material surface along with the stream of evaporated moisture, which affects the aerodynamics of neighboring jets emitted from a multi-needle or multi-wire electrode. It means that the optimum spacing of pins is larger than theoretically predicted. This conclusion is supported by our own research ${ }^{[26]}$ and literature data which indicate that single-pin electrode performs better that the multi-pin electrode. ${ }^{[27]}$ The same effect is expected for multi-wire discharge electrode.

\subsection{Effect of air humidity}

Even though the air humidity plays significant role in the process of drying, its effect on the EHD performance has rarely been studied. Air humidity was measured in several studies by $\mathrm{Lai}^{[28]}$ to calculate the Sherwood number but no explicit relationship for relative humidity was given. Bai et al. ${ }^{[29]}$ presented results of vacuum freeze drying, which revealed better performance of EHD drying at ambient temperature $18^{\circ} \mathrm{C}$ and relative humidity of $45 \%$ versus vacuum freeze drying (conditions were not specified, however).

To fill this gap in the knowledge we performed targeted research on EHD drying of sliced white champignons at various humidity levels controlled by dehumidifier. ${ }^{[30]}$ The results show that high air humidity is detrimental for the performance of EHD drying. Decreasing air humidity from 70 to $30 \%$ significantly increased drying rate (drying rate constant increased more than threefold from $0.12-0.13$ to $0.45-0.5 \mathrm{~h}^{-1}$ ). These experiments confirmed that low air humidity is definitely desirable in EHD drying.

\subsection{Depression of material temperature}

Among various electrically-induced phenomena in EHD drying ${ }^{[2,25]}$ is a noticeable temperature drop in the boundary layer at the liquid-gas interface ${ }^{[31,32]}$, which was identified as large as $8 \mathrm{~K}$ per 100 micrometers. ${ }^{[33]}$ Usually temperature depression of wet material is a result of water evaporation, which depends on the gradient of water vapor 
pressure at the liquid-gas interface. The maximum value of temperature depression could be calculated through absolute air humidity $Y\left(\mathrm{~kg} \mathrm{H}_{2} \mathrm{O}\right)\left(\mathrm{kg}^{-1}\right.$ dry air $)$

$$
T_{D B}-T_{W B}=\frac{\Delta H_{W B}}{c_{H}}\left(Y_{s W B T}-Y\right)
$$

where $T_{D B}, T_{W B}$ denote respectively the dry- and wet-bulb temperatures (K), $\Delta H_{W B}$ is the latent heat of evaporation at wet bulb temperature $\left(\mathrm{kJ} \mathrm{kg}^{-1}\right), c_{H}$ quantifies the humid heat $\left(\mathrm{kJ} \mathrm{kg}^{-1} \mathrm{~K}^{-1}\right)$, and $Y_{\text {SWBT }}$ stands for the absolute air humidity at wet bulb temperature. ${ }^{[34]}$ Our own research aimed at measuring temperature of the wet paper towel with thermal imaging camera revealed noticeably difference between air/material temperatures during EHD drying under controlled humidity of $11 \%$ and different air velocities. ${ }^{[35]}$

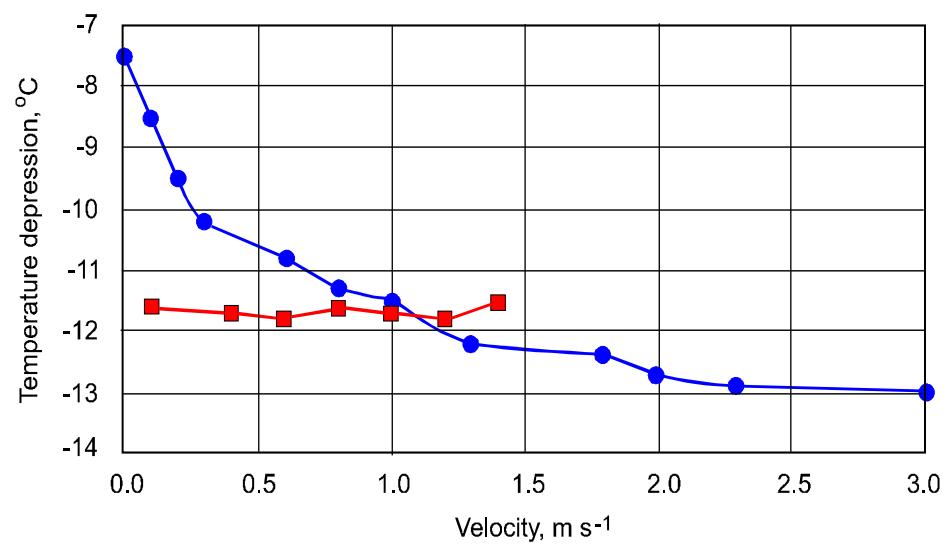

Fig. 1 Magnitude of temperature depression for paper towel exposed to forced air flow at $21.6^{\circ} \mathrm{C}$ (blue points) and ionic wind (red points) generated at 9.5-15 kV.

It is evident that the temperature drop in humid air reflects typical psychrometric curve leveling off at high air velocity (above $6 \mathrm{~ms}^{-1}$ ). Thus, the cooling effect of air flow is directly related to air velocity. In contrast, temperature drop due to ionic wind demonstrated completely different behavior. The range of ionic wind velocities below $1.0 \mathrm{~ms}^{-1}$ corresponded to electric field strength $3-4 \mathrm{kVcm}^{-1}(9.5-12 \mathrm{kV})$, whereas ionic wind velocity above $1.0 \mathrm{~ms}^{-1}$ was induced by electric field above $4 \mathrm{kVcm}^{-1}(13-15 \mathrm{kV})$. Interestingly, temperature drop due to ionic wind is larger than the effect of similar air flow at the range of low velocities, while is smaller for the velocity above $1.0 \mathrm{~ms}^{-1}$. However, it should be noted that EHD-induced temperature of the material surface never attains the wet bulb temperature at convective air flow, which in this case is $13^{\circ} \mathrm{C}$ at $\mathrm{RH}=11 \%$. Interestingly, the cooling effect of EHD was found practically independent of ionic wind velocity up to 1.5 $\mathrm{ms}^{-1}$ above which the breakdown occurred because of excessively high electric field intensity. 


\section{Large-Scale EHD dryers}

\subsection{Prototype EHD dryers}

It appears that the first prototype EHD dryer has been designed in Ukraine, in 1989 and tested for sliced apples. ${ }^{[36]}$ The dryer has been built as a three-band conveyor unit fed with wet material at the upper band and discharged from the lower band. Although the dryer operates continuously with respect to material flow down from band-to-band the air in the dryer is basically stagnant. It means that moisture released from wet material builds-up air humidity and concentrations of volatile compounds and ionization products such as ozone. Therefore, after certain period the feeder is stopped and the empty dryer is blown with fresh ambient by a draft fan. The drying cycle is then repeated with the new batch of a drying material. The bands $0.8 \times 0.3 \mathrm{~m}$ are driven at controlled velocity from 0.1 to $1 \mathrm{~m} / \mathrm{min}$. The needles in discharge electrodes with optimum packing density of 500 needles per $1 \mathrm{~m}^{2}$ are made from molybdenum and powered with 10 to $30 \mathrm{kV}$ AC at $50 \mathrm{~Hz}$. The density of current about $0.01 \mathrm{~A} \mathrm{~m}^{-2}$ and power of $100 \mathrm{~W} \mathrm{~m}^{-2}$ results in apple temperature by $20 \mathrm{deg}$ higher than the ambient temperature. Energy consumption for drying apple slices from 85 to $20 \% \mathrm{wb}$ is on the order of $0.95-1.1 \mathrm{kWh}$ per $\mathrm{kg}$ of evaporated water.

Another prototype of EHD continuous dryer is based on two belt conveyors $0.3 \mathrm{~m}$ wide and $3 \mathrm{~m}$ overall length with inter-stage mixing of the material. ${ }^{[37]}$ Belts tilted at $11.5^{\circ}$ are driven at fixed velocity of $0.33 \mathrm{~ms}^{-1}$. Wire-type discharge electrode is made from stainless steel wire $0.5 \mathrm{~mm}$ in diameter with $5 \mathrm{~cm}$ spacing between neighboring wires. The wires arranged in parallel through a cable bus are connected to reversible polarity DC power supply with regulated voltage from 1 to $50 \mathrm{kV}$ and current from 0 to $0.3 \mathrm{~mA}$.

Tests with wet sand at 8-12 \% wb in a 2-cm layer with $2.52 \mathrm{~cm}$ gap between discharge electrode and the material surface revealed drying enhancement by 1.35 at $12 \mathrm{kV}$ and throughput of $3.1 \mathrm{~kg}$ of evaporated water per 1 hour. This dryer can be used for processing of granular materials in size up to $10 \mathrm{~mm}$ such as sand, gravel, preformed (extruded) pastes as well as sliced or diced fruits and vegetables.

\subsection{Pilot-scale EHD dryers}

As of year 2018 there is no information on commercially available EHD dryers. However, large EHD dryers of various designs have been custom-made in China for research purpose $^{[38]}$. These dryers are basically of two types: (i) multi-band dryer in vertical arrangement (GXJ-2) that can be aggregated into one unit (GXJ-16), and (ii) vertical cylindrical dryer (GTJ-1.7) with vibrated shelves (Fig. 2).

The overall size is $1.6 \times 1.7 \times 2.4 \mathrm{~m}$ (for GXJ-2) and $5.2 \times 3.5 \times 3.1 \mathrm{~m}$ for GXJ-16 where numbers in the model signify drying area in $\mathrm{m}^{2}$. Depending on the material, drying rate is over $3 \mathrm{~kg}$ of water per $\mathrm{m}^{2} \mathrm{~h}$ at corona power of 0.4 and $3.2 \mathrm{~kW}$, respectively. The dryer is 
equipped with dehumidifier with power 0.37 and $5.5 \mathrm{~kW}$, respectively. The dryer GTJ-1.7 is $1.7 \mathrm{~m}$ in diameter with 5 shelves with drying area of $10 \mathrm{~m}^{2}$ vibrated with amplitude $0-4$ $\mathrm{mm}$. Drying rate is over $5 \mathrm{~kg}$ of evaporated water per $\mathrm{m}^{2} \mathrm{~h}$ at corona power $2.2 \mathrm{~kW}$. These dryers were used to dehydrate various whole and cut fruits and vegetables including specific plants used in Chinese medicine.
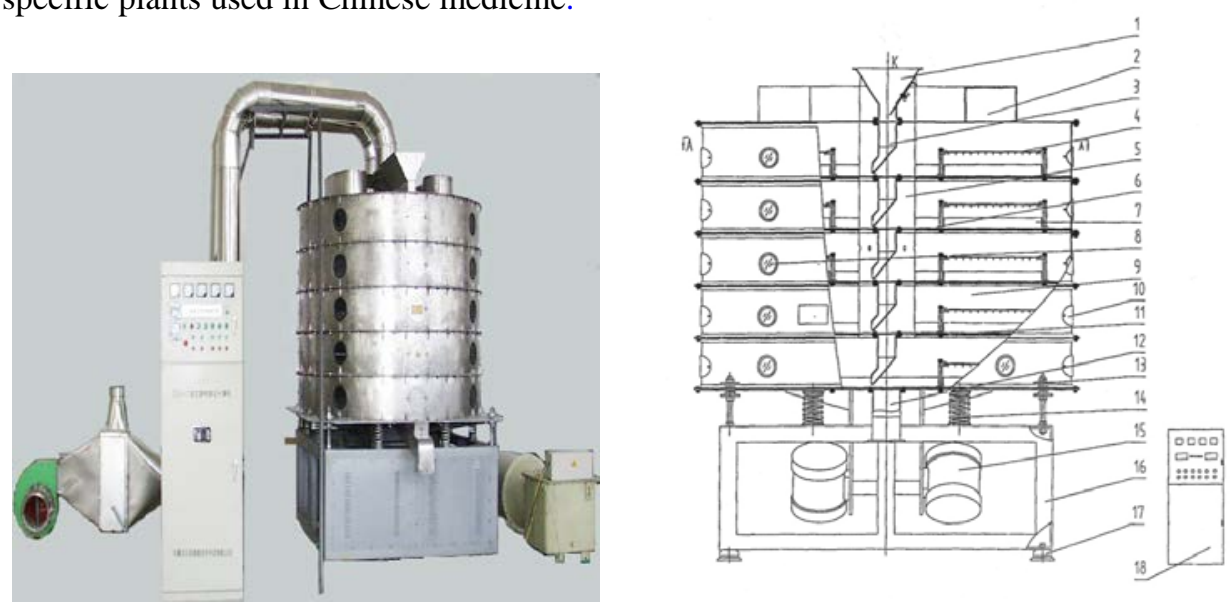

Fig. 2 The picture and schematics of the EHD dryer model GTJ-1.7. [38]

\section{References}

[1] Bajgai, T. R.; Raghavan, G. S. V.; Hashinaga, F.; Ngadi, M. O. Electrohydrodynamic drying - A concise overview. Drying Technology 2006, 7(7), 905 -910.

[2] Singh, A.; Orsat, V.; Raghavan, G. S. V. A comprehensive review on electrohydrodynamic drying and high-voltage electric field in the context of food and bioprocessing. Drying Technology 2012, 30(16), 1812-1820.

[3] Zhang, M.; Chen, H.; Mujumdar, A. S.; Zhong, Q.; Sun, J. Recent developments in high-quality drying with energy-saving characteristic for fresh foods. Drying Technology 2015, 33(13), 1590-1600.

[4] Alemrajabi, A. A.; Rezaee, F.; Mirhosseini, M.; Esehaghbeygi, A. Comparative evaluation of the effects of electrohydrodynamic, oven, and ambient air on carrot cylindrical slices during drying process. Drying Technology 2012, 30(1), 88-96.

[5] Dinani, S. T.; Hamdami, N.; Shahedi, M.; Havet, M. Mathematical modelling of hot air/electrohydrodynamic (EHD) drying kinetics of mushroom slices. Energy Conversion and Management 2014, 86, 70-80.

[6] Singh, A.; Vanga, S. K. K.; Nair, G. R.; Gariepy, Y.; Orsat, V.; Raghavan, G. S. V. Electrohydrodynamic drying of sand. Drying Technology 2017, 35(3), 312-322.

[7] Bai, Y.; Yang, Y.; Huang, Q. Combined electrohydrodynamic (EHD) and vacuum freeze drying of sea cucumber. Drying Technology 2012, 30(10), 1051-1055. 
[8] Lai, F. C.; Wang, C. C. Drying of partially wetted materials with corona wind and auxiliary heat. In Proceedings of ESA Annual Meeting on Electrostatics, Minneapolis, USA, June 17-19, 2008; Paper B1.

[9] Zhao, L.; Adamiak, K. EHD flow in air produced by electric corona discharge in pinplate configuration. Journal of Electrostatics 2005, 63 (3-4), 337-350.

[10] Ahmedou, S. A.; Rouaud, O.; Havet, M. Assessment of the electrohydrodynamic drying process. Food and Bioprocess Technology 2009, 2(3), 240-247.

[11] Chen, Y.; Barthakur, N. N.; Arnold, N. P. Electrohydrodynamic (EHD) drying of potato slabs. Journal of Food Engineering 1994, 23(1), 107-119.

[12] Huang, M.; Lai, F. C. Numerical study of EHD-enhanced water evaporation. Journal of Electrostatics 2010, 68(4), 364-370.

[13] Heidarinejad, G.; Babaei, R. Numerical investigation of electro hydrodynamics (EHD) enhanced water evaporation using Large Eddy Simulation turbulent model. Journal of Electrostatics 2015, 77, 76-87.

[14] Zhong, C.; Martynenko, A.; Wells, P.; Adamiak, K. Numerical investigation of the multi-pin electrohydrodynamic dryer: effect of cross-flow air stream. Journal of Food Engineering 2018 (submitted).

[15] Bajgai, T.R.; Hashinaga, F. High electric field drying of Japanese radish. Drying Technology 2001a, 19(9), 2291-2302.

[16] Alemrajabi, A. A.; Rezaee, F.; Mirhosseini, M.; Esehaghbeygi, A. Comparative evaluation of the effects of electrohydro dynamic, oven, and ambient air on carrot cylindrical slices during drying process. Drying Technology 2012, 30(1), 88-96.

[17] Bajgai, T.R.; Hashinaga, T. Drying of spinach with a high electric field. Drying Technology 2001b, 19(9), 2331-2341.

[18] Xue, X.; Barthakur, N.N.; Alli, I. Electrohydrodynamically-dried whey protein: an electrophoretic and differential calorimetric analysis. Drying Technology1999, 17(3), 467-478.

[19] Hashinaga, F.; Bajgai, T. R.; Isobe, S.; Barthakur, N. N. Electrohydrodynamic (EHD) drying of apple slices. Drying Technology 1999, 17(3), 479-495.

[20] Esehaghbeygi, A.; Basiry, M. Electrohydrodynamic (EHD) drying of tomato slices (Lycopersicon esculentum). Journal of Food Engineering 2011, 104(4), 628-631.

[21] Li, F.D.; Li, L.T.; Sun, J.F.; Tatsumi, E. Effect of electrohydrodynamic (EHD) technique on drying process and appearance of okara cake. Journal of Food Engineering 2006, 77(2), 275-280.

[22] Kudra, T.; Martynenko, A. Design considerations for EHD drying. In Proceedings of $20^{\text {th }}$ International Drying Symposium (IDS 2016), Gifu, Japan, 7-10 August, 2016.; Paper P-3-5

[23] Kudra, T.; Martynenko, A. Energy aspects in electrohydrodynamic drying. Drying Technology 2015, 33 (13), 1534-1540. 
[24] Goldman, M.; Goldman, A.; Sigmond, R. S. The corona discharge, its properties and specific uses. Pure and Applied Chemistry 1985, 57 (9), 1353-1362.

[25] Martynenko, A.; Kudra, T. Electrically-induced transport phenomena in EHD drying a review. Trends in Food Science and Technology 2016, 54, 63-73.

[26] Martynenko, A.; Kudra, T.; Yue, J. Multipin EHD dryer: Effect of electrode geometry on charge and mass transfer. Drying Technology 2017, 35 (16), 1970-1980.

[27] Lai, F. C.; Sharma, R. K. EHD - enhanced drying with multiple needle electrode, Journal of Electrostatics 2005, 63, 223-237.

[28] Alem-Rajabi, A.; Lai, F.C. EHD-enhanced drying of partially wetted glass beads. Drying Technology 2005, 23 (3), 597-609.

[29] Bai, Y.; Hu, Y.; Li, X. Influence of operating parameters on energy consumption of electrohydrodynamic drying. International Journal of Applied Electromagnetics and Mechanics 2011, 35, 57-65.

[30] Martynenko, A.; Kudra, T. Electrohydrodynamic drying of white champignons. In Proceedings of EuroDrying $2017-6^{\text {th }}$ European Drying Conference, Liege, Belgium, June 19-21, 2017, 185-186. Poster 39.

[31] Barthakur, N.N. Electrohydrodynamic enhancement of evaporation from $\mathrm{NaCl}$ solutions. Desalination 1990, 78, 455-465.

[32] Hashinaga, F.; Kharel, G.P.; Shintani, R. Effect of ordinary frequency high electric fields on evaporation and drying. Food Science Technology International 1995, 1 (2), 77-81.

[33] Lindsay, A.; Anderson, C.; Slikboer, E.; Shannon, S.; Graves, D. Momentum, heat and neutral mass transport in convective atmospheric pressure plasma-liquid systems and implications for aqueous targets. Journal of Physics D: Applied Physics 2015, 48, 424007 (14 pp).

[34] Pakowski, Z.; Mujumdar, A.S. Basic Process Calculations and Simulations in Drying. In Handbook of Industrial Drying; Mujumdar, A.S., Ed.; CRC Press: Boca Raton, FL, 2015: 51-75.

[35] Martynenko, A.; Kudra, T. 2018 (unpublished results).

[36] Panchenko, M.S.; Panasyuk, A.L.; Mosievich, A.S.; Moroz, G.A. Application of threshold discharge to supply energy in drying of apple slices. Electronic Processing of Materials 1989, 3 (147), 61-64 (in Russian).

[37] Lai, F.C. A prototype of EHD-enhanced drying system. Journal of Electrostatics 2010, 68, 101-104.

[38] Liang, Y-Z.; Ding, C-J. High Voltage Electric Field Drying. In Modern Drying Technologies, 2nd Enhanced Edition; Pan, Y-K.; Wang, X-Z.; Liu, X-D. Eds.; Chemical Industry Press: Beijing, 2007; 840-858 (in Chinese). 